\title{
CHROMOBLASTOMYCOSIS: A RARE CASE REPORT
}

\author{
Subhash Reddy D', K. Arzitha², G. Manmohan ${ }^{3}$
}

${ }^{1}$ Assistant Professor, Department of Dermatology, Venereology \& Leprology, Osmania Medical College and General Hospital.

2Junior Resident, Department of Dermatology, Venereology \& Leprology, Osmania Medical College and General Hospital.

3 Professor and HOD, Department of Dermatology, Venereology \& Leprology, Osmania Medical College and General Hospital.

\section{ABSTRACT}

\section{BACKGROUND}

Chromoblastomycosis belongs to the heterogeneous group of subcutaneous mycoses. It is caused by various pigmented (Dematiaceous) fungi, which gain entry into the skin via traumatic implantation. We would like to share a case report of chromoblastomycosis in a 30-year-old male, who presented to DVL OP Osmania General Hospital with the complaints of slowly progressive, raised itchy lesions over abdomen, limbs and back since 1yr. He has been treated with itraconazole 200mg twice daily. The patient showed favourable response to itraconazole.

\section{KEYWORDS}

Verrucous lesions, Black dots, Elliptical Conidia in LCB Mount black growth on SDA.

HOW TO CITE THIS ARTICLE: Subhash Reddy D, Arzitha K, Manmohan G. Chromoblastomycosis: A rare case report. J. Evolution Med. Dent. Sci. 2016;5(11):478-482, DOI: 10.14260/jemds/2016/109

\section{INTRODUCTION}

Chromoblastomycosis belongs to the heterogeneous group of subcutaneous mycoses. It is caused by various pigmented (Dematiaceous) fungi, which gain entry into the skin via traumatic implantation. Chromoblastomycosis was originally reported from Brazil. Other than India and Brazil, chromoblastomycosis has been reported from Madagascar, Sri Lanka, West Central Africa, Japan, Mexico, etc. According to one report, Madagascar and Brazil represents the most important focus of this fungal disease. In India, Thomas et al. first reported two cases of chromoblastomycosis from Assam. Since then there has been several case reports from the SubHimalayan belt, Western and Eastern coasts.

All these areas have warm and humid climatic conditions and it is seen that the Central and North Western arid zones of the country are free of the disease. Such an environment could be favorable for the growth of the fungus. The etiological agents of chromoblastomycosis have been discovered from soil, wood, vegetable debris and similar substances. Rural males from an agricultural background were commonly affected, which is the common pattern of the disease worldwide. F. pedrosoi is the most common organism causing chromoblastomycosis worldwide and is also the most common isolate in humid tropical climates.

\section{CASE REPORT}

A 30-yr-old male farmer by occupation in Saudi, where he climbs trees to pluck dates presented to DVL OP Osmania General Hospital with chief complaints of raised itchy lesions over body since 1 year. It initially started on right hand as a small nodule later increased in size resulted in ulcer oozing

Financial or Other, Competing Interest: None.

Submission 22-12-2015, Peer Review 16-01-2016,

Acceptance 23-01-2016, Published 08-02-2016.

Corresponding Author:

Dr. Subhash Reddy $D$,

\#1-2-28/2, E-Block,

Kakatiya Nagar, Street No. 3,

Habsiguda, Hyderabad-500007.

E-mail: dsreddyn97@gmail.com

DOI: $10.14260 /$ jemds/2016/109 pus and blood. Similar lesions occurred gradually on forearm, back, abdomen and legs in a month.

\section{On Examination}

Patient is moderately built and nourished. No pallor, clubbing, icterus, oedema, $\mathrm{B} / \mathrm{L}$ inguinal $\mathrm{LN}$ enlarged $2 \times 2 \mathrm{~cm}$ discrete and nontender, soft in consistency. Vitals-stable. Per abdomensoft, no organomegaly.

Multiple well-circumscribed hyperpigmented plaques with verrucous surface with central hypopigmentation and atrophy of size varying from $6 \times 7 \mathrm{~cm}$ to $2 \times 2 \mathrm{~cm}$ distributed over dorsum of right hand, both legs, right knee, abdomen and back. Few lesions showed black dots. (Figure 1).

\section{Palpation}

Nontender, surrounding skin indurated, lesion arising from subcutaneous tissue.

\section{Differential Diagnosis}

Cutaneous leishmaniasis, Sporotrichosis, Chromoblastomycosis, Disseminated DLE, Lupus vulgaris, Atypical mycobacterial infection, Cutaneous anthrax.

\section{Investigations}

- Histopathology

Mild orthokeratosis, epidermis shows preserved basal cell layer with pigment incontinence, moderate lymphocyte, plasma cell, histyocyte infiltrate in the interstitium and perivascular in dermis. Sclerotic bodies present.

- Biopsy repeated for IF study showed no immune deposits.

- CBP, ESR, RFT, LFT, Sr. Electrolytes, CUE were with in normal limits. Mantoux test -ve.

\section{- Gram stain} few bacilli seen. (Figure 6)

- PUS for fungal stain Occasional nonspecific budding yeast cells-suspicious of sporotrichosis.

- Acid Fast Stain No AFB seen

- Chest X-ray Normal cardiac and pleuro-pulmonary fields. 


\section{- Pus for fungal culture}

SDA: black growth seen after 7 days of inoculation. Reverse: black pigment seen (Figure 2)

\section{- On microscopy}

LCB mount showed branching septate hyphae with chains of elliptical conidia morphologically resembling Cladosporium species (Figure 2).

\section{Treatment}

The patient was treated with oral antibiotics and Tab. itraconazole $200 \mathrm{mg}$ twice daily. The lesions started resolving 2 weeks after starting therapy. (Figure 3).
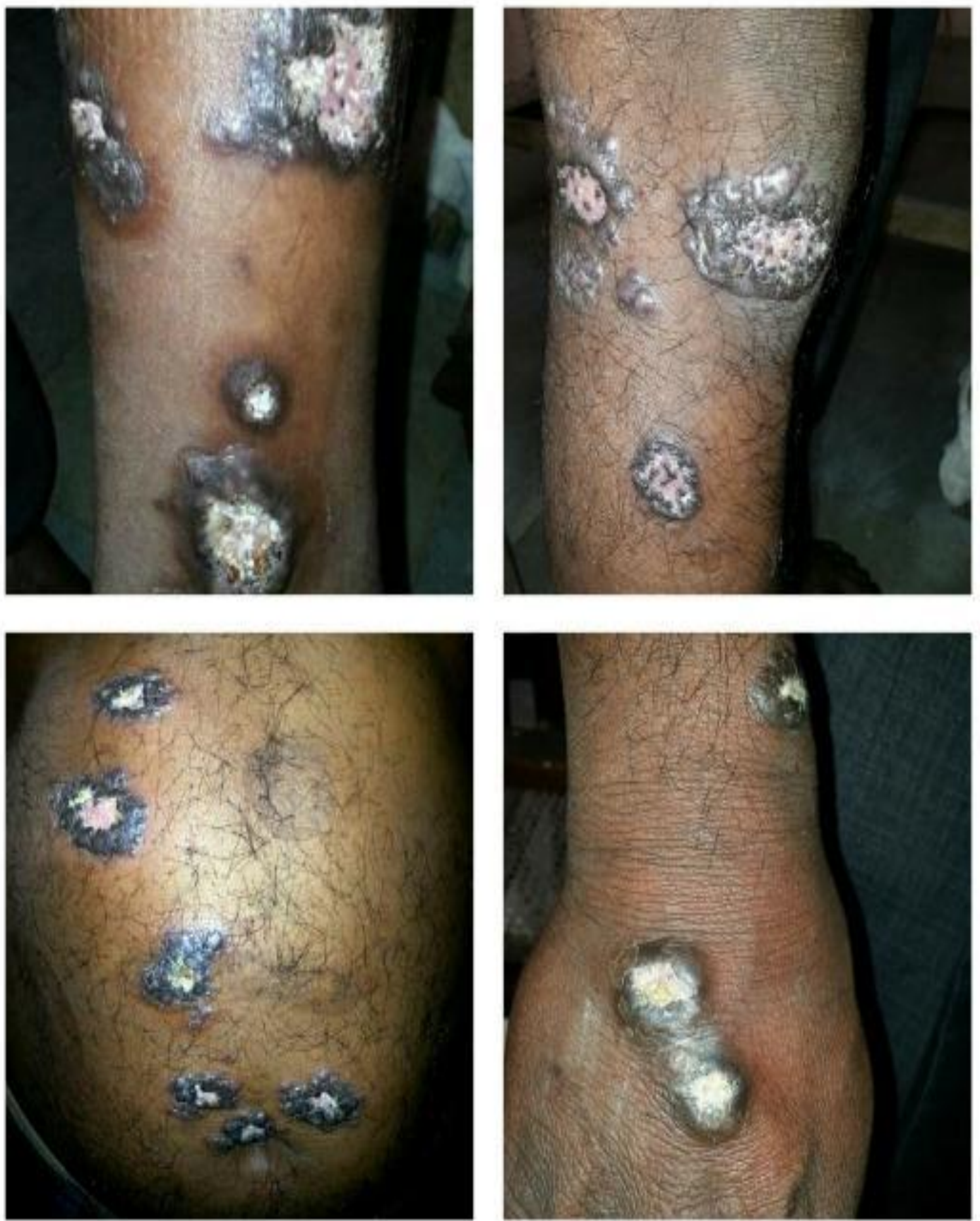

Figure 1 


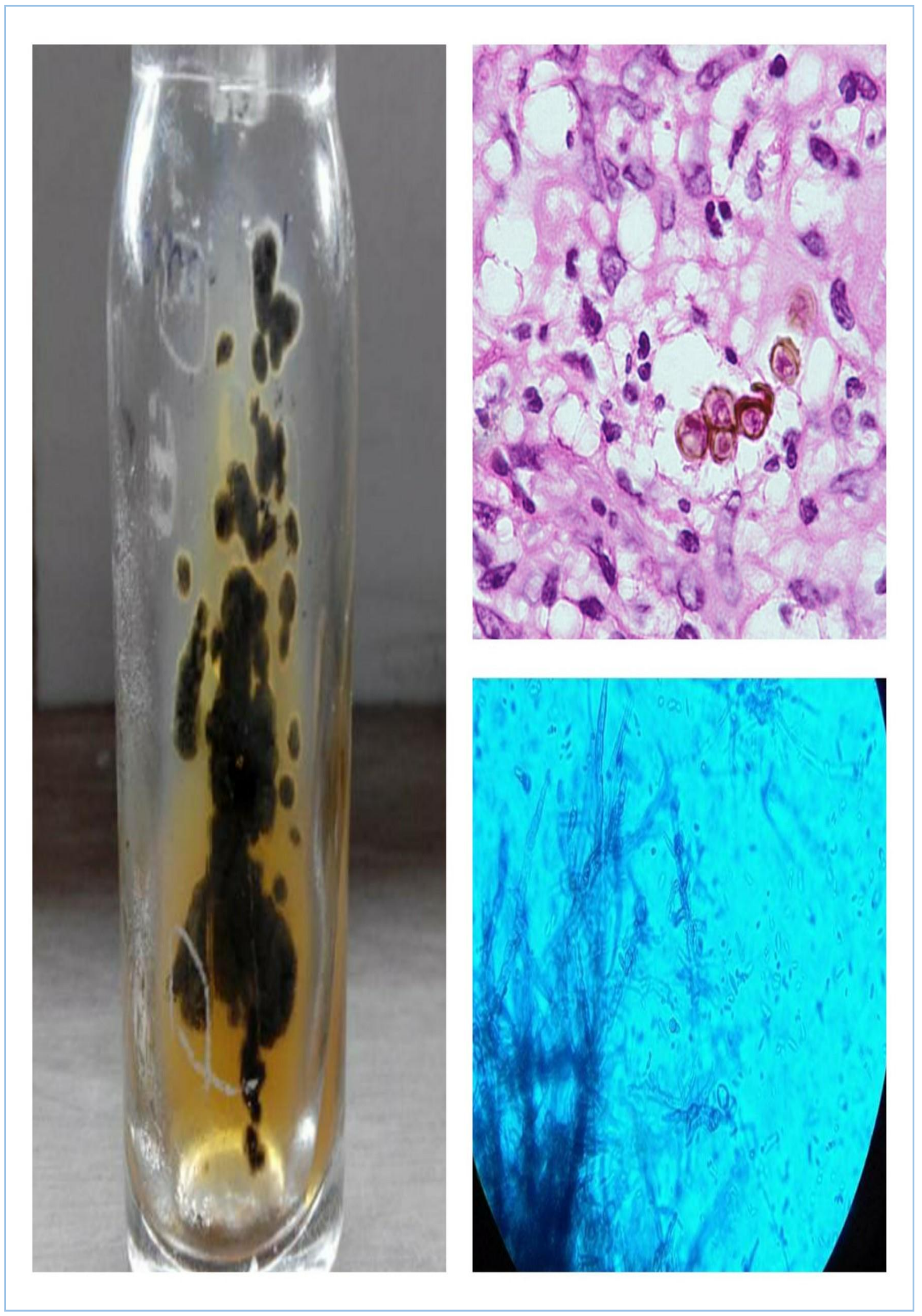

Figure 2 


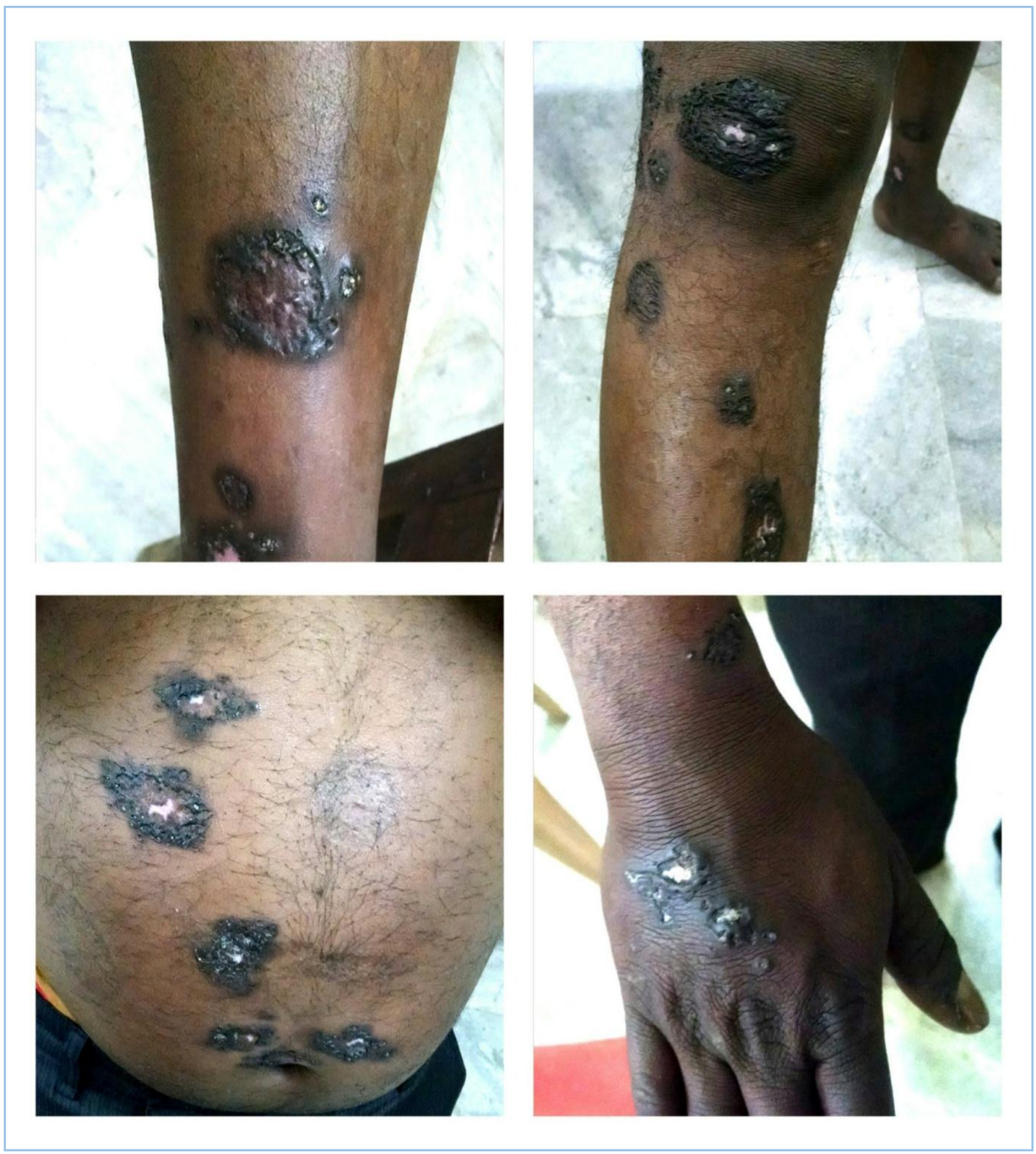

Figure 3: After Treatment

\section{DISCUSSION}

The dematiaceous (Brown-pigmented) fungi are a large and heterogeneous group of moulds that cause a wide range of diseases including phaeohyphomycosis, chromoblastomycosis and eumycotic mycetoma. Among the more important human pathogens are Alternaria species, Bipolaris species, Cladophialophora bantiana, Curvularia species, Exophiala species, Fonsecaea pedrosoi, Madurella species, Phialophora species, Scedosporium prolificans, Scytalidium dimidiatum, and Wangiella dermatitidis.

Clinically, we suspected and confirmed chromoblastomycosis based history of trauma, farmer by occupation, on hypertrophic verrucous nature of the disease, satellite lesions, black dots, sclerotic cells, elliptical conidia on LCB mount, black growth on SDA, favourable response to itraconazole and ruled out phaeohyphomycosis, mycetoma. (No history of grains discharge).

Chromoblastomycosis is a chronic fungal infection of the skin and subcutaneous tissues caused by pigmented or dematiaceous fungi that are implanted into the dermis from the environment.[1] Chromoblastomycosis was originally reported from Brazil. It was first reported from India in 1957 by Thomas et al.[2] Other than India and Brazil, chromoblastomycosis has been reported from Madagascar, Sri Lanka, West Central Africa, Japan, Mexico, Cuba, Dominican Republic, Nepal, Australia and Venezuela.[3],[4],[5],[6] According to one report, Madagascar represents the most important focus of this fungal disease.[7] Brazil is another country reporting large number of cases.[3],[4],[5] In most of these reports, chromoblastomycosis is seen to be a disease of rural 
male agriculturists and the commonest etiological agent is F. pedrosoi.

In India, Thomas et al. first reported two cases of chromoblastomycosis from Assam. [2] Since then, there has been several case reports from the Sub-Himalayan belt, Western and Eastern coasts. Rajendran et al. in 1997 reviewed 30 cases till then from all over India and reported 4 new cases including 2 cases from Jammu and Kashmir and Bihar.[7] Sharma et al. in 1999 also reviewed the Indian scenario and reported four more cases. ${ }^{[8]}$ Kumar et al. reported two cases in 2000 and Sharma A reported four cases from Assam in $2010 .[9],[10]$ In a recently published study, Chandran et al. reported 35 new cases from Central Kerala..[11] All these areas have warm and humid climatic conditions, which is essential for the growth of these fungi and it is seen that the Central and North Western arid zones of the country are free of the disease.[8] Such environmental conditions exist primarily in the Sub-Himalayan belt, Western and Eastern coasts and Southern India.[8],[11] and these regions have been endemic for chromoblastomycosis. Dry climatic conditions do not appear to be favorable for the disease. Among the previously reported cases, 18 were from South India [Andhra Pradesh (5), Karnataka (5), Tamil Nadu (4), Kerala (3), Pondicherry (1)].[7]

The etiological agents of chromoblastomycosis have been discovered from soil, wood, vegetable debris and similar substances. The foothill areas of Western Ghats and the adjoining areas are well known for their rubber plantations where there is plenty of decaying vegetative matter. Such an environment could be favorable for the growth of the fungus. ${ }^{[12]}$ Most of the cases employed in various agricultural tasks including rubber tapping. Rural males from an agricultural background were commonly affected, which is the common pattern of the disease worldwide.[4],[6] The relationship with trauma correlates well with the predominant involvement of extremities among agriculturists. The most common species of fungus isolated was F. pedrosoi. F. pedrosoi is the most common organism causing Chromoblastomycosis worldwide and is also the most common isolate in humid tropical climates.

The infection can be caused by a number of fungi, but the vast majority is caused by Fonsecaea pedrosoi and Cladosporium carrionii.[1] Fonsecaea pedrosoi appears to be the most common etiological agent worldwide as well as in cases reported from warm and humid regions of India. ${ }^{[3],[4],[6],[8]}$ Although overwhelming majority of cases are found on lower limb, slowly progressive verrucous lesions on upper limb should also alert the clinician to the possibility of chromoblastomycosis as was in our case.

Differential diagnoses include cutaneous tuberculosis and all the deep mycoses including mycetoma and nocardiosis. Diagnosis is made by demonstration of fungus in the lesions. This is done definitively through culture of causative species on Sabouraud's dextrose agar. However, an easier and more rapid method of diagnosis is bedside demonstration of sclerotic bodies in $\mathrm{KOH}$ examination.[13] Sclerotic or muriform bodies are thick-walled single cells or cell clusters seen as brown-colored "Copper pennies." They can also be detected in routine $\mathrm{H}$ - and E-stained biopsy specimens. The therapeutic modalities include itraconazole $200 \mathrm{mg}$ daily with or without flucytosine $(30 \mathrm{mg} / \mathrm{kg}$ QID); terbinafine $250 \mathrm{mg}$ daily and in extensive cases intravenous amphotericin B. However, the duration of therapy seems to be prolonged and uncertain. Combination therapy with itraconazole and terbinafine has been shown to be synergistic.[14] Cladosporium carrionii seems to respond more rapidly to terbinafine and itraconazole.[15] However, the duration and dose of therapy for complete cure with no recurrence of lesions, is still to be determined. In our case too Cladosporium responded to itraconazole; however, we are not sure at what dose and for what duration it needs to be continued to ensure complete cure.

\section{REFERENCES}

1. Roderick J Hay. Deep fungal infections. In: Wolff $\mathrm{K}$, Goldsmith LA, Katz SI, Gilchrest BA, Paller AS, Leffell DJ, editors. Fitzpatrick's Dermatology in General Medicine. $7^{\text {th }}$ ed. New York: McGraw Hill; 2008. p. 1833-5.

2. Thomas E, Job CK, Hadley GG. Chromo-blastomycosis. Indian J Med Sci 1957;11:570-3.

3. Silva JP, De Souza W, Rozental S. Chromo-blastomycosis: a retrospective study of 325 cases on Amazonic region (Brazil). Mycopathologia 1998;143:171-5.

4. Minotto R, Bernardi CD, Mallmann LF, et al. Chromoblastomycosis: A review of 100 cases in the state of Rio Grande do Sul, Brazil. J Am Acad Dermatol 2001;44:5859.

5. Mouchalouat Mde F, Gutierrez Galhardo MC, ZancopéOliveira RM, et al. Chromo-blastomycosis: a clinical and molecular study of 18 cases in Rio de Janeiro, Brazil. Int J Dermatol 2011;50:981-6.

6. Kombila M, Gomez de Diaz M, Richard-Lenoble D, et al. Chromoblastomycosis in Gabon. Study of 64 cases. Sante 1995;5:235-44.

7. Rajendran C, Ramesh V, Misra RS, et al. Chromoblastomycosis in India. Int J Dermatol 1997;36:29-33.

8. Sharma NL, Sharma RC, Grover PS, et al. Chromoblastomycosis in India. Int J Dermatol 1999;38:846-51.

9. Kumar B. Chromo-blastomycosis in India: Two more cases. Int J Dermatol 2000;39:800.

10. Sharma A, Hazarika NK, Gupta D. Chromo-blastomycosis in subtropical regions of India. Mycopathologia 2010; 169:381-6.

11. Chandran V, Sadanandan SM, Sobhanakumari K. Chromoblastomycosis in Kerala, India. Indian J Dermatol Venereol Leprol 2012;78:728-33. [PUBMED]

12. Gezuele E, Mackinnon JE, Conti-Díaz IA. The frequent isolation of Phialophora verrucosa and Phialophora pedrosoi from natural sources. Sabouraudia 1972;10:266-73.

13. Goette DK, Robertson D. Transepithelial elimination in chromomycosis. Arch Dermatol 1984;120:400-1.

14. Pradhan SV, Talwar OP, Ghosh A, et al. Chromoblastomycosis in Nepal: a study of 13 cases. Indian J Dermatol Venereol Leprol 2007;73:176-8.

15. Zhang JM, Xi LY, Zhang $\mathrm{H}$, et al. Synergistic effects of terbinafine and itraconazole on clinical isolates of Fonsecaea monophora. Eur J Dermatol 2009;19:451. 